\title{
PLANETARY ATMOSPHERES
}

Edited by C. SAGAN, T. C. OWEN and H. J. SMITH
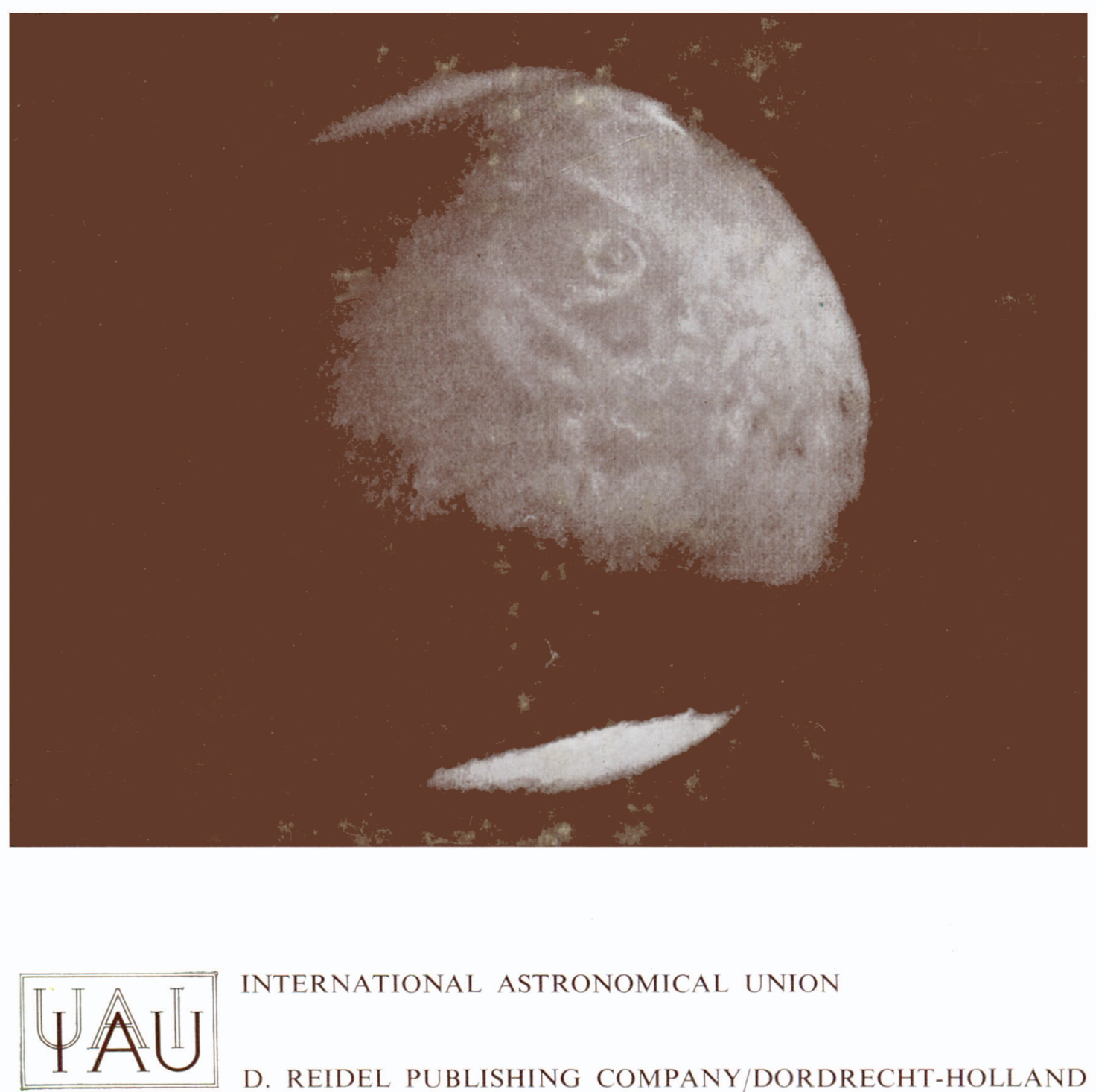

INTERNATIONAL ASTRONOMICAL UNION

D. REIDEL PUBLISHING COMPANY/DORDRECHT-HOLLAND 


\section{PLANETARY ATMOSPHERES}

SYMPOSIUM No. 40

IAU Symposium No. 40 on Planetary Atmospheres brought together more than 100 experts for a week of papers and discussion. One of the 9 sessions was devoted to the outer planets, with principal emphasis on Jupiter. The majority of the sessions were divided approximately equally between Mars and Venus. Special emphasis was given to the atmosphere of Venus as probed by the recent Soviet Venera series, and the degree to which the Russian probe results are consistent with the rapidly increasing information available from spectroscopy of the upper atmosphere and radio astronomy observations of the lower atmosphere and surface characteristics. Models of the Venus atmosphere are now relatively consistent between the various modes of investigation; among the principal remaining puzzles are details of water vapor detectability and abundance, and the nature of the clouds, although considerable evidence was presented at the conference in favour of hydrated ferrous chloride as a principal cloud material. New insights on the Martian large-scale circulation, the total abundance of constituents, the partial pressure of the atmosphere, and the predominantly $\mathrm{CO}_{2}$ character of the polar caps were features eliciting general agreement; one of the major uncertainties of Mars is its exospheric properties. We are approaching a point where the Martian atmosphere is well enough understood for large-scale climatology to be a practical subject for investigation. 
PLANETARY ATMOSPHERES 


\title{
PLANETARY ATMOSPHERES
}

\author{
EDITED BY \\ CARL SAGAN \\ Laboratory for Planetary Studies, Center for Radiophysics and Space Research, \\ Cornell University, Ithaca, N.Y., U.S.A. \\ TOBIAS C. OWEN \\ State University of New York at Stony Brook, \\ Department of Earth and Space Sciences, Stony Brook, N.Y., U.S.A. \\ AND \\ HARLAN J. SMITH \\ Dept. of Astronomy, University of Texas at Austin, Austin, Tex., U.S.A.
}

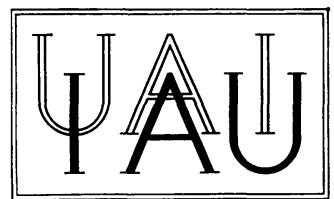

D. REIDEL PUBLISHING COMPANY

DORDRECHT-HOLLAND

1971 


\author{
Published on behalf of \\ the International Astronomical Union \\ by \\ D. Reidel Publishing Company, Dordrecht, Holland
}

All Rights Reserved

Copyright (C) 1971 by the International Astronomical Union

Library of Congress Catalog Card Number 77-140566

ISBN 9027701652

No part of this book may be reproduced in any form, by print, photoprint, microfilm, or any other means, without written permission from the publisher

Printed in Great Britain 


\section{TABLE OF CONTENTS}

Preface

v

List of Participants

XIII

\section{PART I / VENUS}

A. P. Vinogradov, The chemical composition of the atmosphere of Venus 3 Yu. A. Surkov,

B. M. Andreichikov,

O. M. Kalinkina, and

I. M. Grechischeva

C. A. Barth

Exospheric temperature of Venus from Mariner 5

17

J. R. Herman,

Models of the Venus ionosphere

R. E. Hartle, and

S. J. Bauer

J. B. Pollack and

Venus: Determination of atmospheric parameters

D. Morrison from the microwave spectrum

N. N. Kroupenio

Peculiarities of $\mathrm{mm}$ and $\mathrm{cm}$ radiowave propagation in the Venus atmosphere

C. W. Snyder

Some consequences of critical refraction in the Venus atmosphere

J. W. Chamberlain

A two-parameter theory for Venus spectra

T. Owen and

A new short-wavelength carbon dioxide band in the

H. P. Mason spectrum of Venus

W. S. Benedict

Calculations of $\mathrm{CO}_{2}$ energy levels: The $\tilde{A}^{1} B_{2}$ state

R. A. Hanel,

High spectral resolution interferometric planetary

V. G. Kunde, observations in the $7-25 \mu$ region

T. Meilleur, and

G. Stambach

J. A. Westphal

Limb darkening observations of Venus from $5 \mu$ to $18 \mu$ 
W. F. Libby and

P. Corneil

J. Seckbach and

W. F. Libby

D. L. Coffeen

G. P. Kuiper

G. T. Sill

C. Sagan

P. B. Boyce

W. M. Irvine,

J. C. Higdon, and

S. J. Ehrlich

W. G. Egan and

K. M. Foreman

J. M. Mead

A. P. Ingersoll

H. C. van de Hulst
Water on Venus?

Vegetative life on Venus? Or investigations with algae which grow under pure $\mathrm{CO}_{2}$ in hot acid media and at elevated pressures

Venus cloud contrasts 84

On the nature of the Venus clouds

Geochemical problems in the production of the Venus clouds

The trouble with Venus

\section{PART II / MARS}

\section{A. Optical Properties}

Colorimetry of Martian features by means of area scanning

Longitudinal variations, the opposition effect, and monochromatic albedos for Mars

Mie scattering and the Martian atmosphere

The contribution of atmospheric aerosols to the Martian opposition effect

Ultraviolet polarization measurements of Mars and the opacity of the Martian atmosphere

Some problems of anisotropic scattering in planetary atmospheres

\section{B. $\mathrm{CO}_{2}$ Absorption}

L. D. Kaplan and

An interpretation of the Mars spectrum taken by the

L. D. Gray Young

Connes

Observations of the Martian $1.2 \mu \mathrm{CO}_{2}$ bands

Variations of the Martian $\mathrm{CO}_{2}$ abundance with Martian season 

A. Woszczyk
Relative elevation differences revealed by near infrared $\mathrm{CO}_{2}$ bands on Mars
D. P. Cruikshank
Spectroscopic determination of surface pressure and elevation differences on Mars

\section{Water Vapor Absorption}

R. A. Schorn

R. G. Tull

S. J. Little

U. Fink and

G. P. Kuiper

A. P. Ingersoll

C. A. Barth,

W. G. Fastie,

C. W. Hord,

J. B. Pearce,

K. K. Kelly,

A. I. Stewart,

G. E. Thomas,

G. P. Anderson, and

O. F. Raper

J. D. Anderson

G. Münch,

G. Neugebauer, and

S. C. Chase

R. B. Leighton,

N. H. Horowitz,

B. C. Murray,

R. P. Sharp,

A. H. Herriman,

A. T. Young,

B. A. Smith,

M. E. Davies, and

C. B. Leovy
The spectroscopic search for water on Mars: A history

The latitude variation of water vapor on Mars

223

237

A report on Martian atmospheric water vapor near opposition, 1969

High altitude interferometer spectra of Mars

Mars: Occurrence of liquid water

\section{Mariner Results}

Mariner 6: Ultraviolet spectrum of Mars upper atmosphere

Mariner 1969: Results of the infrared radiometer experiment

Mariner 6 and 7 television pictures: Preliminary analysis 


\section{E. Cloud Motions and Atmospheric Dynamics}

G. S. Golitsyn

G. S. Golitsyn

G. de Vaucouleurs

W. A. Baum and

L. J. Martin

M. Shimizu
A. Dalgarno and
T. C. Degges

Estimates of boundary layer parameters in the atmospheres of the terrestrial planets

The theory of similarity for large-scale motions in planetary atmospheres

Cloud activity on Mars near the equinox: Comparison of the 1937 and 1969 oppositions

Cloud motions on Mars

\section{F. Upper Atmospheres}

The effect of atmospheric dynamics on the upper atmosphere phenomena of Mars and Venus

$\mathrm{CO}_{2}^{+}$dayglow on Mars and Venus

\section{PART III / OUTER PLANETS}

N. B. Hopkins and Variations in the color of Jupiter

W. M. Irvine

L. M. Trafton and

R. Wildey

J. A. Westphal

W. B. Streett

S. F. Dermott

V. G. Teifel,

L. A. Usoltzeva, and

G. A. Kharitonova

J. D. Poll

L. S. Galkin,

L. A. Bugaenko,

O. I. Bugaenko, and

A. V. Morozhenko
The effective temperature of Jupiter's equatorial belt during the 1965 apparition

Observations of Jupiter's cloud structure near $8.5 \mu$

Phase behavior of light gas mixtures at high pressures

Atmospheric depths of Jupiter, Saturn, and Uranus

The spectral characteristics and probable structure of the cloud layer of Saturn

Estimate of the $\mathrm{H}_{2}$ abundance in the atmosphere of Uranus from the pressure induced spectrum

The spectrum of Uranus in the region $4800-7500 \AA$ 
W. E. McGovern Upper limit of hydrogen and helium concentrations on Titan

PART IV/SCIENTIFIC DEDICATION OF THE 107-INCH REFLECTOR

Remarks made at the scientific dedication of the 107 -inch reflector, October 30 , 1969 